\title{
Information Flow and Strategic Consensus in Organizations
}

\author{
Raj V. Mahto ${ }^{1} \&$ Peter S. Davis ${ }^{2}$ \\ ${ }^{1}$ Department of Finance, International, Technology and Entrepreneurship, Anderson School of Management, The \\ University of New Mexico, Albuquerque, USA \\ ${ }^{2}$ Belk College of Business, University of North Carolina Charlotte, Charlotte, USA \\ Correspondence: Raj V. Mahto, Department of Finance, International, Technology and Entrepreneurship, \\ Anderson School of Management, The University of New Mexico, Albuquerque, NM 87131-0001, USA. Tel: \\ 1-505-277-2423. E-mail: rmahto@unm.edu
}

$\begin{array}{lcc}\text { Received: June 1, 2012 } & \text { Accepted: July 24, 2012 } & \text { Published: September 1, } 2012 \\ \text { doi:10.5539/ijbm.v7n17p1 } & \text { URL: http://dx.doi.org/10.5539/ijbm.v7n17p1 }\end{array}$

\begin{abstract}
This study investigate strategic consensus in organizations. Previous studies have examined consensus in the top management team and between the top management team and middle managers. In our study we propose the importance of considering consensus among lower level employees. We argue that intra-organizational flow of information influences the development of consensus at the middle and lower levels of the organizational hierarchy. We also argue that the hierarchical level of the information source plays a crucial role in developing consensus. We analyze these relationships with data collected from a large service organization over two time periods.
\end{abstract}

Keywords: strategic consensus, information flow, organizational hierarchy, boundary role personnel, middle managers

\section{Introduction}

Researchers have suggested that organizations are goal-directed social entities (Cyert\& March, 1963). Commitment of organizational membersto an organizational goal is essential for organizational success (Hrebiniak\& Snow, 1982; Dess \& Origer, 1987; Polzer, Milton, \& Swann Jr., 2002; Li \&Hambrick, 2005). In order to align efforts of different organizational constituents towards a common goal, normative literature in strategic management has emphasized various practices such as the development of mission statements (Ansoff, 1965), participation of organizational constituents in decision making (Fiol, 1994), and the development of goal-oriented reward systems. However, given the composition of organizations (i.e. the diversity of members of an organization), ensuring the awareness and commitment of all organizational constituents to organizational goals is difficult (Polzer et al, 2002).

The presence of consensus among the organization's members about organizational goals is a major determinant of the customers' perception of the organization's conduct in its external environment (Kopelman, Brief, \&Guzzon, 1990). The awareness of goals acts as a normative guide for the behavior of organizational employees. Employees, who are either uninformed or uncommitted to the organization's goals, exhibit inconsistent behavior which may result in substantial damage to the organization's cause.This is especially true in the context of middle and lower level employees, who generally do not participate in the organization's strategic planning (Wooldridge \& Floyd, 1989). On the other hand, the CEO and the members of the top management team (TMT) possess the knowledge of strategic goals and are generally committed to it because of their participation in shaping the final strategic goal for organization (Dooley, Fryxell, \& Judge, 2000). However, some organizational scholars have argued that despite consensus on organizational goals, the conduct of organizational members may be inconsistent with goals of organization as the members use different means to achieve the set goal (Mintzberg, 1994). Thus, there is need for consensus on both the goal and on the means to achieve the decided goal (Bourgeois, 1985).

Reviews of previous literature suggest that researchers have recognized the importance of consensus among organizational members (both on goal and means to achieve the goal) (Bourgeiois, 1980; Dess, 1987; Priem, Harrison, \& Muir, 1990).Consensus has been found to increase not only organizational performance 
(Kellermanns, Walter, Floyd, Lechner, \& Shaw, 2011; Pagell\& Krause, 2002; Rapert, Velliquette, \& Garretson, 2002) but also innovation (Bantel \& Jackon, 1989). However, mostof the research has focused on the consensus among members of TMT (Bourgeois, 1980, 1985; Dess, 1987; Dess\& Origer, 1987; Priem, 1990) or between TMT and middle level managers (Wooldridge \& Floyd, 1989, 1990) and the consequences of the consensus on organizational outcomes. Employees at the lower levels of the organizational hierarchy or boundary role personnel are missing completely from research on consensus. This is especially true in the context of service organizations, where boundary role personnel because of their unique position in firm's interaction with its task environment (Adams, 1976) are best suited for managing critical interfaces with customers (Aldrich \&Herker, 1977, Keller, 1993). They reflect the organization's image and policy in every interaction with customers (Schneider, 1993) thereby creating avenues for shaping a positive or negative image in the customer's mind (Keller, 1993). It is therefore crucial for organizations that lower level employees are aware of not only organization goals but also of the means to achieve the goals. In the absence of consensus among lower level employees, the realization of organization goals is placed in jeopardy (Jemison, 1984; MacMillan, 1978; Floyd \& Wooldridge, 1992). This requires the lower level employees to share consensus with both the TMT and middle level employees of the organization. Our argument is that the scope of consensus in the organization should include not just the TMT and middle level employees but also the lower level employees or boundary role personnel. However, creating consensus among different level of employees is easier said than done. Research on the antecedents of consensus in the literature is sparse.There is, however, normative work which suggests that consensus across organizational levels can be achieved through the imposition of a structural framework such as formalizing rules and procedures (John \& Rue, 1991). This requires the creation of a more mechanistic organization structure, which given the level of competition and change in the environment may be inappropriate and place the organization at a comparative disadvantage.

In this paper, we draw upon marketing theories of brand equity to propose that consensus among the organization's employees, especially the middle and lower-level employees, can be achieved by increasing the level of internal information flow or communication in the organization. We also argue that the hierarchy of informationsource (TMT, middle and lower level employee) will have a differential impact on the informationreceivers'advancement towards consensus with rest of the organization's members. We finally test our model using data from a service organization.

\subsection{Intra-organizational Information Flow and Consensus in Organizations}

Information flow is the lifeblood of the organization and an organization cannot exist in absence of this flow (Rogers \& Rogers, 1976). Information flows play various crucial roles in organizations (Jivan\&Zarandi, 2012). For example, marketing researchers have suggested that the flow of product information (e.g. frequency of advertisements) increases the brand awareness of the consumer or customer (Moreland \&Zajonc, 1979). The assumption underlying this argument is that the repetition of information enhances the likelihood and extent to which a person attends to, comprehends, and retains the information (Hovland, Janis, \& Kelly, 1953). The subject's increasing familiarity with the information (Zajonc, 1968) raises the likelihood and amount of attitude change (Hovland, et al., 1953). Inside organizations, information flow has a similar impact on its receivers (Markos\&Sridevi, 2010). As the information flow (about organizational goals and means) increases in the organization, the familiarity of employees about organizational goals and means increases significantly (Kellermanns\& Floyd, 2005). The familiarity with organizational goal and means guides the behavior of the employees in a consistent manner resulting in increased congruence with other layers of the organization.

\subsection{Hierarchy of Information Source and Consensus}

The flow of information involves three components - the source of information, the information transfer medium, and the receiver of the information. Previous researchers have suggested that information source attributes, such as trustworthiness (Levin, Cross, \& Abrams, 2002), competence (Levitt \& March, 1988), and proximity to the receiver (Roger, 1980), play a significant role in the transfer process. The three levels of hierarchy in the organization, the TMT, middle managers (MM), and boundary role personnel (BRP) will have different degrees of associated trustworthiness, competence, and proximity attributes. For example, members of the TMT are involved in planning the organizational goal, and hence, will naturally be assumed to be more competent and provide more trustworthy information about organizational goalsthan a source from any other level of the organizational hierarchy. However, the proximity between a source from the TMT and a receiver from BRP is less than the proximity between source and receiver from same hierarchical level (e.g. a BRP source \& a BRP receiver, or a MM source \& a MM receiver). Information transfers across organizational levels are less proximate (e.g. from a TMT source to a BRP receiver or vice versa). While closer proximity increases the development of personal bonds between source and receiver, it also significantly increases the potential for 
distortion in transfer process and decreases the utility of transfer process (e.g. Morrison, 1993). In transferring information across levels, the power difference between source and receiver, where source has higher power or authority compared to receiver, brings a structure to the flow of information between them. This suggests that the vertical downward communication should have the highest level of information transfer utility in the organization. Horizontal communication on the other hand significantly reduces the utility of transfer process. For example, transfer involving a TMT source, who is at the top of the organizational hierarchy, and a BRP receiver, who is at the lowest level of organization, should have highest utility despite the lowest proximity between the two (e.g. Rodgers \& Rodgers, 1980). The primary reason for this enhanced utility is the highest power difference between the two. The significant power difference negates the chances of distortion in the form of personal communication during the transfer process. It follows that the transfer involving a source and a receiver from the middle managers will have significantly lower utility despite closer proximity between them. This is because the lower distance and power differences between them increases the potential for personal relationships, which significantly increases the potential for distortion in the transfer process. Personal relationshipsonly increase communication significantly when the kind of communication that involved is other than organizational (Rodgers \& Rodgers, 1980). Similar processes will influence the transfer process across other organizational hierarchies. Overall, the hierarchical level of the source will play a crucial role in the information transfer process.

\subsection{Hypotheses}

Emphasizing the importance of information flow in organizations, Doz and Prahalad (1984) suggested that TMTs of multinational organizations use communication to develop a single perspective and cohesiveness in an otherwise diverse and complex organizational structure. Poole $(1978,493)$ also noted that communication serves as the basis for control and coordination in organization and linked organization communication to its effectiveness. Intra-organizational communication aligns diverse organization constituents and facilitates the control and coordination of work efforts in organizations (Senge, 1990).According to strategic management researchers, frequent and effective communication between the organization's decision makers and those responsible for implementation at the operations or lower levels of the organization developsa commonality of shared perception and strategic vision across the organization levels (Jemison, 1984; Floyd and Wooldridge, 1992). Frequent communication helps to develop common definitions of terms between the messenger and receiver, thus aiding the understanding of the meaning of communication andminimizing the distortion in communication channels (Roger and Roger, 1976). Use of technology, which enhances the frequency of communication and in-group interaction, is correlated with consensus in the group (Watson, DeSanctis, \&Poole, 1988). This leads us to our first hypothesis.

Hypothesis 1: An increased level of intra-organizational communication affects the development of strategic consensus in the organization.

There are three hierarchical levels of information sources in an organization - the TMT, the MM, and the BRP. At the same time these sources are also the receivers of information. However, in the context of present study, there are only two information receivers - the MM and the BRP. This is because the TMT cannot finalize the organizational goals without having consensus among them. Thus, consensus in the organization basically means the consensus of employees at the MM and the BRP level with the members of the TMT. The information flow in the organization is of two types vertical and horizontal. Horizontal information flow involves flow in a single hierarchical level where the information transfer occurs among the members of a hierarchical level (e.g. from a BRP member to another BRP member).The vertical information flow involves multiple levels of the organization hierarchy and information never flows between members of same hierarchy (e.g. from TMT member to BRP member).Organizational information flows consist of a mixture of horizontal and vertical communication. However, when the information in question is organizational and not personal, then most of the information flow is vertical (Simon \& Other, 1950).Also, downward information flows are more frequent than upward flows (Simon \& Other, 1950). There is often relatively little upward communication in an organization (Walker \& Guest, 1952).

TMT members, being the designers of organizational goals, are the most knowledgeable about future directionality of the organization and the strategy to be implemented to realize those goals (Huber \& Power, 1985).Directing the efforts of other organizational members towards organizational goals requires the TMT initiate the communication that shares this critical information with other organization members (Markos\&Sridevi, 2010). This makes the TMT members the most frequent initiator of information flow in organization than individuals at the lower level (Roger \& Roger, 1976). However, despite initiating a high proportion of the messages, the TMT members receive a low proportion of information from lower levels of 
organizational hierarchy.

$B R P$ as Information Receiver.Information flow involving a BRP receiver can have three sources of information TMT, MM, \& BRP. Employees at the lowest level of the organizational hierarchy turn to middle managers for guidance in their daily organizational life. Due to this frequent interaction and the accessibility of MM, the BRP receiver rely on $\mathrm{MM}$ for all kinds of organizational guidance, thereby significantly increasing perceived reliability of the MM source. Also, the daily interaction increases a BRP's perceived trustworthiness of the MM source. However, the power difference between the BRP and MM ensures the distortion in the information flow will remain at a minimum level. For the BRP, MM are the reliable information source about strategy and strategic means.

Organizational scholars using the resource dependence perspective suggest that the TMTat the apex of the organizational hierarchy are the most influential source of information and their information will have higher impact onBRP compared to information from MM (Van de Ven\& Walker, 1984). However, in most organizations access to the TMT is restricted to protect the TMTfrom the information overload that may resultif they are allowed to communicate with all organization members (Rogers \& Rogers, 1976). Thus, BRP will not have much access to information from the TMT. The BRP are the lowest in hierarchy and message from them will have lowest reliability. Morrison (1993) argues that peers will be preferred for some types of information and supervisor for others. Greller and Herold (1975) found that employees rated supervisors as the most informative sources of role information. The information exchange between employees and supervisors is mostly work related compared to information exchange between peers where it is more personal. Supervisors being higher in hierarchy than peers will have more information about the strategy and work compared with information peers have. This leads to us to next hypothesis.

Hypothesis 2a: Communication from TMT will positively influence BRP consensus.

Hypothesis 2b: Communication from MM will positively influence BRP consensus.

Hypothesis 2c: TMT communication will have the highest relative influence and BRP communication will have the least relative influence on BRP consensus. Relative influence of communication from $T M T, M M, \& B R P$ on $B R P$ consensus will follow pattern: $T M T>M M>B R P$.

$M M$ as information receiver. A MM information receiver will also have three different source of organization information - the TMT, MM and BRP. However, as mentioned previously, the information flow in organizations is mostly downward (Rogers \& Rogers, 1976) so most of the organizational information is communicated from the TMT level. The power difference between TMT and MM provide a structure to the information flow. The power difference reduces the information distortion during the transfer process. MM's perceived competence of the TMT will be also high compared to the perceived competence of either a MM or a BRP source, because the TMT source is generally involved in the organizational decision making. Also, the TMT source is at higher hierarchical level than either a MM or BRP source, this increases MM perception of trustworthiness of a TMT source in providing correct organizational information. Therefore, the communication from the TMT will have greater influence and reliability than communication from MM and BRP. The perceived competence of a BRP source will be significantly lower than the perceived competence of a similar MM source as BRP are at a lower hierarchical level. This hierarchical difference between MM and BRP sourcesmay also create suspicion about the trustworthiness of BRP's organizational information due to ego - a MM may have difficulty trusting a source from a lower level employee. While a MM source and a MM receiver share same level of organizational hierarchy, thereby significantly increasing the potential of information distortion (Morrison, 1993) the perceived competence and trustworthiness of source for information will be significantly higher relative to a BRP source. This leads us to third and final hypothesis.

Hypothesis 3a: Communication fromTMT will positively influence MM consensus.

Hypothesis 3b: Communication from MM will positively influence MM consensus.

Hypothesis 3c: TMT communication will have the highest relative influence and BRP communication will have the least relative influence on $M M$ consensus. Relative influence of communication from $T M T, M M, \& B R P$ on $M M$ consensus will follow pattern: $T M T>M M>B R P$.

\section{Methods}

The hypotheses proposed in this study were tested using sample data collected through a quasi-longitudinal field study conducted in a large, multi-location bank in the western U.S.The study was prompted by an organizational crisis; changes in the market conditions lead to a noticeable decline in the market share and other performance indicators at the bank. The arrival of new Chief Executive Officer (CEO) led to an adjustment in the bank 
strategy. The new strategy was prepared by the "retail strategy committee", which included thirteen TMT members of the bank. One of the researchers acted as the observer and facilitator to the strategy planning process. As an observer, the researcher interacted with "retail strategy committee" members and interviewed other senior executives and middle managers selected from other functional areas such as customer service, marketing, and operations. During this process data were collected from organizational members through a questionnaire. The data were collected at two different points of time from the organization's employees at all three levels of the organizational hierarchy. The same survey questionnaires were used at both times in collecting the data. We obtained a final usable sample of 255 in the first time period and 230 in the second time period. In both samples majority of subjects were in the lower level of organizational hierarchy (74\% in first and $72 \%$ in the second). Middle managers comprised $20 \%$ and $22 \%$ percent of data in first and second sample respectively. The rest were members of TMT. We tested the hypotheses proposed in this study on both sets of data separately.

\subsection{Measurements}

The measures of study variable used in this study are as follows.

Strategic Consensus. The strategic consensus was measured using a two-step process. In the first step, we measured the strategy of subject organization using a set of eighteen items identified from our review of the strategy literature. These items represented important components of strategy (Hambrick, 1983; Dess\& Davis, 1984). The face validity of these items was assessed during an on- site interview with members of the TMT. These items represented three different dimensions of the organization's strategy. The three underlying dimensions of organization strategy we used in this study are: customer service strategy, product/service strategy, and sales strategy.

- $\quad$ Customer Service Strategy. Customer service strategy was measured using seven-item scale. The respondents provided answers on a 7-point, Likert-type scale ranging from $1=$ rarely and activity to $7=$ always an activity. A sample item is, "Taking time to provide individualized service to customers."

- Product/Service Strategy.Product/service strategywas captured using a four-item scale. The respondents provided answers on a 7-point, Likert-type scale ranging from $1=$ rarely and activity to $7=$ always an activity. A sample item is, "Providing products/services that customers perceive as unique to your organization."

Sales Strategy.Sales strategy was measured using seven-item scale. The respondents provided answers on a 7-point, Likert-type scale ranging from $1=$ rarely an activity to $7=$ always an activity. A sample item is, "Selling products to current customers."

In the second step, we calculated a score for strategic consensus for each of the three representative strategy content dimensions, for both the middle managers (MM) and the boundary role person's (BRP)lack of strategic awareness of the "planned" strategy of the organization. This was done by calculating the absolute value of the difference between the aggregate score for the focal individual on that strategic dimension and the mean score for the members of the top management team. This approach to the assessment of an organization's intended strategy, by averaging the perceptual data across top managers, has been employed in previous studies (Sutcliffe, 1994). Historically, numerous studies have documented situations in which averaged perceptions were quite accurate even though almost all individuals' perceptions were inaccurate (Starbuck \& Bass, 1963). We obtained three scores of strategic consensus each for MM \& BRP. These composite score were called MM customer service strategy consensus, MM product service strategy consensus, and MM sales strategy consensus. Three similar BRP strategic consensus dimensions scores were created for the analysis.

Information flow: Following Goldhaber \& Rogers (1979), we used two dimensions of information flow to assess its quality. The two dimensions used are communication frequency and usefulness of information.

Communication frequency. We measured communication frequency using a fifteen-item scale. These items captured the frequency with which messages were received from each communication source (TMT, MM, BRP and Peers) about the strategy of the organization. Items of the scale were 7-point, Likert- type, where $1=$ Not at all to $7=$ every day.The items of the scale were summed to create a single score communication frequency.

- Usefulness of Information. The usefulness of information flow was measured using a fifteen-item scale. These items asked respondents about the strategic variables used for capturing the present strategy of the organization. Communication usefulness was measured using a 7-point, Likert type scale, ranging from $1=$ not at all useful to $7=$ very useful. The items of the scale were summed to create a single composite score called information usefulness. 


\section{Analysis}

We performed maximum-likelihood factor analysis on both samples of data to assess the dimensionality of our measures. We examined the solutions with oblique rotations as the underlying factors were assumed to be correlated with each other. For testing the hypotheses proposed in this study, we used multiple regressions with consensus as our dependent variable. We compared the relative strength of information flow from different communication sources on consensus at MM and BRP levels by comparing standardized regression coefficients.

\subsection{Measurement Properties}

Three factors with eigenvalues greater than 1 emerged during exploratory maximum likelihood factor analysis performed using eighteen items from organizational strategy. We analyzed the solution with oblique rotation due to assumption of correlation among underlying dimensions of organization's strategy. The three factors which emerged accounted for almost $60 \%$ of the variance in the items. The results indicated that the items of the underlying factors loaded heavily on their appropriate factor while the cross loadings were generally weak. We repeated the analysis using the data from second time period. The results indicated findings similar to those from time period one. Again three factors emerged during the analysis, which together accounted for almost $59 \%$ of variance in the items. The items of underlying factors again loaded heavily on their appropriate factors while cross loading on other factors were low.

Six factors with eigenvalues greater than 1 emerged during exploratory maximum likelihood factor performed using thirty items of organization information flow in both data samples. We analyzed the solution with oblique rotation due to assumption of correlation among underlying dimensions of information flow. The six factors together accounted for $70 \%$ and $73 \%$ of variance in time period 1 and time period 2 samples, respectively.

We also assessed the reliability of our scale by performing reliability analysis. All the study measures had Cronbach's alpha $(\alpha)$ greater than .70 (the lowest alpha was information frequency from TMT $\alpha=.79$ ). The reliability of all the measures from both data samples is presented in tables 1 and 2 .

Table 1. Time period 1, Means, standard deviations, and correlation among study variables

\begin{tabular}{|c|c|c|c|c|c|c|c|c|c|c|}
\hline & 1 & 2 & 3 & 4 & 5 & 6 & 7 & 8 & 9 & 10 \\
\hline Organizational hierarchy level & 1 & & & & & & & & & \\
\hline TMT communication frequency & $-.145^{*}$ & 1 & & & & & & & & \\
\hline MM communication frequency & .011 & $.409 * *$ & 1 & & & & & & & \\
\hline BRP communication frequency & .064 & $.378 * *$ & $.667 * *$ & 1 & & & & & & \\
\hline TMT information usefulness & $-.149 *$ & $.498 * *$ & $.235 * *$ & $.189^{* *}$ & 1 & & & & & \\
\hline MM information usefulness & .024 & $.293 * *$ & $.598 * *$ & $.430 * *$ & $.653 * *$ & 1 & & & & \\
\hline BRP information usefulness & .066 & $.274 * *$ & $.452 * *$ & $.667 * *$ & $.476^{* *}$ & $.659 * *$ & 1 & & & \\
\hline Consensus on customer service & .084 & .058 & $.268 * *$ & $.236^{* *}$ & $.199 * *$ & $.384 * *$ & $.250 * *$ & 1 & & \\
\hline Consensus on product/service & .081 & .023 & $.171^{* *}$ & $.173 * *$ & $.170 * *$ & $.200 * *$ & $.204 * *$ & $.412 * *$ & 1 & \\
\hline Consensus on sales strategy & .054 & .107 & $.239 * *$ & $.182 * *$ & $.231 * *$ & $.376^{* *}$ & $.230 * *$ & $.663^{* *}$ & $.433 * *$ & 1 \\
\hline Means & 2.68 & 18.15 & 19.32 & 16.01 & 23.59 & 24.69 & 21.04 & 36.95 & 12.19 & 38.12 \\
\hline Standard deviations & .59 & 5.32 & 5.96 & 7.25 & 6.56 & 6.70 & 8.37 & 6.15 & 4.70 & 6.18 \\
\hline Alpha $(\alpha)$ & NA & .79 & .85 & .89 & .85 & .88 & .92 & .87 & .79 & .87 \\
\hline
\end{tabular}

\footnotetext{
* Correlation is significant at the 0.05 level (2-tailed).

** Correlation is significant at the 0.01 level (2-tailed).
} 
Table 2. Time period 2, Means, standard deviations, and correlations among study variables

\begin{tabular}{|c|c|c|c|c|c|c|c|c|c|c|}
\hline & 1 & 2 & 3 & 4 & 5 & 6 & 7 & 8 & 9 & 10 \\
\hline Organizational hierarchy level & 1 & & & & & & & & & \\
\hline TMT communication frequency & -.098 & 1 & & & & & & & & \\
\hline MM communication frequency & -.122 & $.443 * *$ & 1 & & & & & & & \\
\hline BRP communication frequency & .060 & $.385^{* *}$ & $.637 * *$ & 1 & & & & & & \\
\hline TMT information usefulness & -.113 & $.496 * *$ & $.310 * *$ & $.299 * *$ & 1 & & & & & \\
\hline MM information usefulness & -.126 & $.361 * *$ & $.615^{* *}$ & $.344 * *$ & $.614 * *$ & 1 & & & & \\
\hline BRP information usefulness & .007 & $.351 * *$ & $.504 * *$ & $.677 * *$ & $.524 * *$ & $.677 * *$ & 1 & & & \\
\hline Consensus on customer service & .122 & $.185^{* *}$ & $.206^{* *}$ & .106 & $.328 * *$ & $.352 * *$ & $.293 * *$ & 1 & & \\
\hline Consensus on product/service & .075 & .100 & $.255^{* *}$ & .124 & $.252 * *$ & $.274 * *$ & $.173 *$ & $.556^{* *}$ & 1 & \\
\hline Consensus on sales strategy & .044 & $.277 * *$ & $.247 * *$ & $.168^{*}$ & $.303 * *$ & $.279 * *$ & $.198 * *$ & $.576^{* *}$ & $.420 * *$ & 1 \\
\hline Means & 2.69 & 16.62 & 18.82 & 15.52 & 22.22 & 23.50 & 20.17 & 36.71 & 14.41 & 37.01 \\
\hline Standard deviations & .55 & 5.14 & 6.10 & 7.25 & 7.03 & 6.88 & 8.17 & 6.53 & 4.96 & 6.79 \\
\hline Alpha $(\alpha)$ & NA & .82 & .87 & .88 & .88 & .87 & .90 & .89 & .81 & .87 \\
\hline
\end{tabular}

** Correlation is significant at the 0.01 level (2-tailed).

* Correlation is significant at the 0.05 level (2-tailed).

\section{Results}

Means, standard deviations, and correlations among study variables for time periods 1 and 2 data samples are shown in tables 1 and 2 respectively. The consensus on three dimensions of organization's strategy (customer service strategy, product/service strategy, and sales strategy) are positively related to frequency and usefulness of communication, with some exceptions, from all three levels of organizational hierarchy in both samples. Frequency of information flow from TMT is has no correlation with any of consensus dimension in the first time period sample. In the second time period sample, it is not related to consensus on product/service strategy.

The results of the regression analysis for BRP consensus for time periods 1 and 2 is displayed in tables 3 and 4 , respectively. While the regression results for MM consensus for time period 1 and 2 is shown in tables 5 and 6 , respectively.

Table 3. Time period 1, standardized regression coefficients for BRP strategic consensus

\begin{tabular}{|c|c|c|c|c|c|c|}
\hline \multirow[b]{2}{*}{ Independent Variable } & \multicolumn{2}{|c|}{$\begin{array}{c}\text { Customer service strategy } \\
\text { consensus } \\
\end{array}$} & \multicolumn{2}{|c|}{$\begin{array}{c}\text { Product/service strategy } \\
\text { consensus }\end{array}$} & \multicolumn{2}{|c|}{ Sales strategy consensus } \\
\hline & $\begin{array}{l}\text { Standardized } \\
\text { Beta }(\beta)\end{array}$ & Sig. & $\begin{array}{l}\text { Standardized } \\
\text { Beta }(\beta)\end{array}$ & Sig. & $\begin{array}{l}\text { Standardized } \\
\text { Beta }(\beta)\end{array}$ & Sig. \\
\hline TMT communication frequency & -.095 & .378 & -.166 & .142 & -.085 & .435 \\
\hline MM communication frequency & .104 & .459 & .034 & .821 & .118 & .407 \\
\hline BRP communication frequency & .029 & .835 & .028 & .858 & .042 & .771 \\
\hline TMT information usefulness & .059 & .630 & .208 & .118 & .127 & .313 \\
\hline MM information usefulness & $.348 * *$ & .017 & .078 & .607 & $.286^{*}$ & .053 \\
\hline BRP information usefulness & -.045 & .744 & .066 & .662 & -.111 & .427 \\
\hline Adjusted $\mathrm{R}^{2}$ & \multicolumn{2}{|c|}{.137} & \multicolumn{2}{|c|}{.049} & \multicolumn{2}{|l|}{.109} \\
\hline
\end{tabular}

** Significant at the 0.05 level.

* Significant at the 0.10 level. 
Table 4. Time period 2, standardized regression coefficients for BRP strategic consensus

\begin{tabular}{lcccccc}
\hline \multicolumn{1}{c}{ Dependent Variable $\rightarrow$} & $\begin{array}{c}\text { Customer service strategy } \\
\text { consensus }\end{array}$ & $\begin{array}{c}\text { Product/service strategy } \\
\text { consensus }\end{array}$ & \multicolumn{2}{c}{ Sales strategy consensus } \\
\hline Independent Variable & $\begin{array}{c}\text { Standardized } \\
\text { Beta }(\beta)\end{array}$ & Sig. & $\begin{array}{c}\text { Standardized } \\
\text { Beta }(\beta)\end{array}$ & Sig. & $\begin{array}{c}\text { Standardized } \\
\text { Beta }(\beta)\end{array}$ & Sig. \\
\hline TMT communication frequency & -.037 & .734 & -.116 & .288 & .117 & .281 \\
MM communication frequency & .086 & .519 & .200 & .138 & .096 & .478 \\
BRP communication frequency & $.252^{*}$ & .088 & -.131 & .381 & .006 & .970 \\
TMT information usefulness & $.223^{*}$ & .064 & $.245^{*}$ & .046 & $.207^{*}$ & .090 \\
MM information usefulness & .042 & .781 & .083 & .581 & .050 & .745 \\
BRP information usefulness & .239 & .129 & -.027 & .866 & -.095 & .554 \\
Adjusted $\mathrm{R}^{2}$ & .096 & & & .056 & & .064 \\
\hline
\end{tabular}

** Significant at the 0.05 level.

* Significant at the 0.10 level.

Table 5. Time period 1, standardized regression coefficients for MM strategic consensus

\begin{tabular}{lcccccc}
\hline \multicolumn{1}{c}{ Dependent Variable $\rightarrow$} & \multicolumn{2}{c}{$\begin{array}{c}\text { Customer service } \\
\text { strategy consensus }\end{array}$} & $\begin{array}{c}\text { Product/service strategy } \\
\text { consensus }\end{array}$ & \multicolumn{2}{c}{ Sales strategy consensus } \\
\hline Independent Variable & $\begin{array}{c}\text { Standardized } \\
\text { Beta }(\beta)\end{array}$ & Sig. & $\begin{array}{c}\text { Standardized } \\
\text { Beta }(\beta)\end{array}$ & Sig. & $\begin{array}{c}\text { Standardized } \\
\text { Beta }(\beta)\end{array}$ & Sig. \\
\hline $\begin{array}{l}\text { TMT communication } \\
\text { frequency }\end{array}$ & -.085 & .696 & -.061 & .765 & -.016 & .943 \\
$\begin{array}{l}\text { MM communication } \\
\text { frequency }\end{array}$ & .268 & .286 & .382 & .124 & .034 & .898 \\
$\begin{array}{l}\text { BRP communication } \\
\text { frequency }\end{array}$ & -.295 & .258 & .106 & .674 & -.012 & .966 \\
$\begin{array}{l}\text { TMT information } \\
\text { usefulness }\end{array}$ & .099 & .703 & $.495^{* *}$ & .041 & .188 & .472 \\
$\begin{array}{l}\text { MM information } \\
\text { usefulness }\end{array}$ & $.743^{*}$ & .009 & $.485^{*}$ & .055 & .181 & .507 \\
$\begin{array}{l}\text { BRP information } \\
\text { usefulness }\end{array}$ & -.350 & .156 & .151 & .514 & .028 & .913 \\
Adjusted R & & & & & & \\
\hline
\end{tabular}

** Significant at the 0.05 level.

* Significant at the 0.10 level. 
Table 6. Time period 2, standardized regression coefficients for MM strategic consensus

\begin{tabular}{|c|c|c|c|c|c|c|}
\hline \multirow{2}{*}{$\begin{array}{l}\text { Dependent Variable } \rightarrow \\
\text { Independent Variable }\end{array}$} & \multicolumn{2}{|c|}{$\begin{array}{l}\text { Customer service } \\
\text { strategy consensus }\end{array}$} & \multicolumn{2}{|c|}{$\begin{array}{c}\text { Product/service strategy } \\
\text { consensus }\end{array}$} & \multicolumn{2}{|c|}{ Sales strategy consensus } \\
\hline & $\begin{array}{c}\text { Standardized } \\
\text { Beta }(\beta)\end{array}$ & Sig. & $\begin{array}{l}\text { Standardized } \\
\text { Beta }(\beta)\end{array}$ & Sig. & $\begin{array}{c}\text { Standardized } \\
\text { Beta }(\beta)\end{array}$ & Sig. \\
\hline $\begin{array}{l}\text { TMT communication } \\
\text { frequency }\end{array}$ & .048 & .787 & -.103 & .547 & .077 & .671 \\
\hline $\begin{array}{l}\text { MM communication } \\
\text { frequency }\end{array}$ & .288 & .195 & $.533 * *$ & .019 & .321 & .173 \\
\hline $\begin{array}{l}\text { BRP communication } \\
\text { frequency }\end{array}$ & -.212 & .359 & -.002 & .992 & -.098 & .669 \\
\hline $\begin{array}{l}\text { TMT information } \\
\text { usefulness }\end{array}$ & .357 & .177 & $.418^{*}$ & .073 & .249 & .332 \\
\hline MM information usefulness & .004 & .989 & -.137 & .591 & -.212 & .461 \\
\hline $\begin{array}{l}\text { BRP information } \\
\text { usefulness }\end{array}$ & .084 & .718 & -.033 & .877 & .279 & .235 \\
\hline Adjusted $\mathrm{R}^{2}$ & .162 & & .208 & & .109 & \\
\hline
\end{tabular}

** Significant at the 0.05 level.

* Significant at the 0.10 level.

Our first hypothesis suggested a positive influence of intra-organizational communication on consensus. A glance at the results of regression tables suggest that usefulness of information has an impact on consensus at both MM and BRP levels; but frequency of communication has almost no impact on the formation of consensus at either hierarchical level. Even though most of the regression coefficients are not significant, the directionality of the relationship is consistent with our hypothesis. Overall, the support for hypothesis one is mixed.

Hypotheses $2 \mathrm{a}, 2 \mathrm{~b}$, and $2 \mathrm{c}$ concern the influence of communication source (from different hierarchical levels) on BRP consensus. As can be seen in tables 3 and 4, only the usefulness of information from the TMT has a marginally significant impact on BRP consensus in the time period 2 sample. In time period 1 sample, usefulness of information from MM has significant impact on two dimensions of consensus (customer service strategy and sales strategy). Thus, the results for hypothesis $2 \mathrm{a}$ and $2 \mathrm{~b}$ are inconclusive. Additionally, given the inconclusive results for hypotheses $2 \mathrm{a}$ and $2 \mathrm{~b}$, the result for hypothesis $2 \mathrm{c}$ remains inconclusive.

Finally, Hypotheses $3 \mathrm{a}, 3 \mathrm{~b}$, and $3 \mathrm{c}$ concerned the influence of communication source from different hierarchical levels on MM consensus. As can be seen in the tables 3 and 4, only the usefulness of information from the TMT and $\mathrm{MM}$ have a positive impact on MM consensus in the time period 1 sample. However, the results are not consistent across all three dimensions of consensus. In the time period 2 sample, the MM communication frequency and TMT usefulness of information have a positive impact on product/service strategy consensus. In the time period 1 sample, MM information usefulness has a positive influence on two dimensions of consensus customer service and product/service strategy. Overall, we find partial support for hypothesis $3 \mathrm{a}$ and $3 \mathrm{~b}$. However, in the absence of concrete results, findings for hypothesis $3 \mathrm{c}$ are inconclusive.

\section{Discussion}

This study contributes to the strategy literature in several ways. First, we provide evidence of the influence of information flow on the development of strategic consensus in the organization. In this process, we find that the usefulness of information is more important than the frequency of information flow. Our findings are consistent with the suggestions of Rodgers and Rodgers (1980), who proposed that most of the communication in organization is downward as we found that communication from BRP source has no impact on consensus at MM or BRP level.

This study also contributes to the literature by being the first to examine the antecedents of strategic consensus at middle and lower levels of the organizational hierarchy. Even though previous researchers have looked at the 
consensus at the TMT level (Dess, 1987; Dess\& Origer, 1987) and MM level (Wooldridge \& Floyd, 1990), the research on consensus at the BRP level is nonexistent. This is the first study to include all three organizational levels in examining consensus.

Finally this study makes a significant contribution to the strategy literature by arguing that the hierarchical position of the information source in the organization determines their influencing power on consensus.

There are also limitations associated with this study. The first major limitation is the source of data. The data were collected from a single organization. This limits the generalizability of the findings of this study. Additionally, the survey method was used to collect the data from respondents creating a potential for common method bias in the data. However, the patterns of correlation among the study variables do not seem to indicate this bias. Another major limitation is that causal inferences cannot be drawn from this study because of our use of cross-sectional data (we analyzed two time period samples independently). Although we collected data at two different periods of time; the design of the study did not allow us to track individuals over the duration of the study. Future researchers could rectify this quasi-longitudinal problem by tracking individuals over time or using an experimental design which provides potential for rigorous control over the subjects.

Despite these limitations, we believe this study makes an important contribution to strategy field by helping us to understand the process involved in the development of consensus in an organization.

\section{References}

Aldrich, H., \& Herker, D. (1977). Boundary Spanning Roles and Organization Structure. Academy of Management Review, 2(2), 217-230.

Ansoff, H.I. (1965). Corporate Strategy: An Analytical Approach to Business Policy for Growth and Expansion. McGraw-Hill, New York.

Bantel, K., \& Jackon, S. (1989). Top management and innovations in banking: Does the composition of the top team make a difference? Strategic Management Journal, 10, 107-124.

Bourgeois, L. J. (1980). Performance and consensus. Strategic Management Journal, 1, 227-248.

Bourgeois, L. J. (1985). Strategic goals, perceived uncertainty, and economic performance in volatile environments. Academy of Manage Journal, 28(3), 548-573.

Cyert, R. M., \& March, J. G. (1963). A Behavioral Theory of the Firm. Prentice-Hall, Englewood Cliffs, NJ.

Dess G. G. (1987). Consensus on strategy formulation and organizational performance: competitors in a fragmented industry. Strategic Management Journal, 8, 259-277.

Dess G. G., \& Davis P. S. (1984). Porter's (1980) generic strategies as determinants of strategic group membership and organizational performance. Academy of Management Journal, 27(3), 467-488.

Dess, G. G., \& Origer, N. K. (1987). Environment, structure, and consensus in strategy formulation. Academy of Management Review, 12.

Dooley, R.S., \& Fryxell, G. E. (1999). Attaining decision quality and commitment from dissent: The moderating effects of loyalty and competence in strategic decision making teams. Academy of Management Journal, 42(4), 389-402.

Dooley, R.S., Fryxell, G. E., \& Judge, W. Q. (2000). Belaboring the not-so-obvious: Consensus, commitment, and strategy implementation speed and success. Journal of Management, 26(6), 1237-1257.

Doz, Y., \& Prahalad, C. K. (1984). Patterns of strategic control within multinational corporations. Journal of International Business Studies, Fall, 55-72.

Fiol, C. M. (1994). Consensus, diversity, and learning in organizations. Organization Science, 5(3), 403-420.

Floyd, S. W., \& Woolridge, B. (1992). Managing strategic consensus: The foundation of effective implementation. Academy of Management Executive, 6(4), 27-39.

Goldhaber, G. M., \& Rogers, D. P. (1979). Auditing organizational communication systems: The ICA communication audit. Dubuque, IA: Kendall/Hunt.

Greller, M.M., \& Herold, D.M. (1975). Sources of Feedback: A Preliminary Investigation. Organizational Behavior and Human Performance, 13, 244-256.

Hambrick, D. (1981). Strategic Awareness within top management teams. Strategic Management Journal, 2, 263-278. 
Hambrick, D. C. (1983). High profit strategies in mature capital goods industries: A contingency approach. Academy of Management Journal, 26, 687-707.

Hovland, C. I., Janis, I. L., \& Kelley, H.H. (1953). Communication and persuasion; Psychological studies of opinion change. New Haven, CT: Yale University Press.

Hrebiniak L.G., \& Snow, C.C. (1982). Top-management agreement and organizational performance. Human Relation, 12, 1139-1158.

Huber, G. P., \& Power, D. J. (1985). Retrospective reports of strategic-level managers: Guidelines for increasing their accuracy. Strategic Management Journal, 6(2), 171-180.

Jemison, D. B. (1984). The importance of boundary spanning roles in strategic decision-making. Journal of Management Studies, 21(2), 131-151.

Jivan, M. E., \& Zarandi, M. (2012). Factors Effective on Knowledge Management in Service-Oriented Organizations (Senior Managers Opinion UsingAnalytical Hierarchy Process (AHP). International Journal of Business and Management, 7(5), 150-158.

John, C. H., \& Rue, L. W. (1991). Research notes and communications coordinating mechanisms, consensus between marketing and manufacturing groups, and marketplace performance. Strategic Management Journal, 12, 549-555.

Keller, K. L. (1993). Conceptualizing, measuring, and managing customer-based brand equity. Journal of Marketing, 57(1), 1-22.

Kellermanns, F. W., Walter, J., Floyd, S.W., Lechner, S., \& Shaw, J.C. (2011). To agree or not to agree? A meta-analytical review of strategic consensus and organizational performance. Journal of Business Research, 64(2), 126-133.

Kellermanns, F.W., \& Floyd, S. (2005). Strategic consensus and constructive confrontation: unifying forces in the resource accumulation process. In: Floyd, S., Ross, J., Jacobs, C., \&Kellermanns, F.W., editors. Innovating strategy process. Oxford: Blackwell Publishing. pp. 149-162.

Kellermanns, F.W., Walter, J., Lechner, C., \& Floyd, S.W. (2005). The lack of consensus about strategic consensus: advancing theory and research. Journal of Management, 31(5), 719-737.

Kopelman, R.E., Brief, A.P., \& Guzzo, R. A. (1990). The role of climate and culture in productivity. In Schneider B (Ed.), Organizational climate and culture. San Francisco: Jossey-Bass.

Levin, D. Z., Cross, R., \& Abrams, L. C. (2002). Why Should I TrustYou? Predictors of Interpersonal Trust in a Knowledge Transfer Context. Presented at the Academy of Management Annual Meeting, Denver, CO, August 9-14, 2002.

Li, J., \& Hambrick, D.C. (2005). Factional groups: a new vantage on demographic faultlines, conflict, and disintegration in work teams. Academy of Management Journal, 48, 5, 794-813.

Markos, S., \& Sridevi, M. S. (2010). Employee Engagement: The Key to Improving Performance. International Journal of Business and Management, 5(12), 89-96.

Mintzberg H. (1994). The fall and rise of strategic planning. Harvard Business Review, 72(1), 107-114.

Moreland, R. L., \& Zajonc, R. B. (1979). Exposure effects may not depend on stimulus recognition. Journal of Personality and Social Psychology, 37(6), 1085.

Pagell, M., \& Krause, D. R. (2002). Strategic consensus in the internal supply chain: exploring the manufacturing-purchasing link. International Journal of Product Research, 40(13), 3075-3092.

Polzer, J. T., Milton, L. P., \& Wann, Jr., W. B. (2002). Capitalizing on diversity: Interpersonal congruence in small work groups. Administrative Science Quarterly, 47, 296-324.

Poole, M. S. (1978). An information-task approach to organizational communication. Academy of Management Review, 3(3), 493-504.

Priem, R. L. (1990). Top management team group factors, consensus, and firm performance. Strategic Management Journal, 11, 469-478.

Priem, R. L., Harrison, D. A., \& Muir, N. K. (1995). Structured conflict and consensus outcomes in group decision making. Journal of Management, 21(4), 691-710.

Rapert M.I., Velliquette, A., \& Garretson, J.A. (2002). The strategic implementation process.Evokingstrategic 
consensus through communication. Journal of Business Research, 55(4), 301-10.

Rodgers, E. M., \& Rodgers, R. (1980). Communication in organizations. Free Press: New York.

Schneider, B. (1983). An interactionist perspective on organizational effectiveness: A comparison of multiple models. Academic Press, New York, pp. 27-54.

Starbuck W. H., \& Bass F. M. (1963). An experimental study of risk-taking and the value of information in a new product context. Journal of Business, 40, 155-165.

Sutcliffe, K. (1994). What executives notice: Accurate perception in top management teams. Academy of Management Journal, 37, 1360-1378.

Van d. Ven, A. H., \& Walker, G. (1984). The Dynamics of interorganizational coordination consensus. Administrative Science Quarterly, 29, 598-621.

Walker, C. R., \& Guest, R. H. (1952). The Man on the Assembly Line. Harvard Business Review, 30(3), 71-83.

Watson, R. T., DeSanctis, G., \& Poole, M. S. (1988). Using a GDSS to facilitate group consensus: Some intended and unintended consequences. MIS Quarterly, September, 464-477.

Wooldridge, B., \& Floyd, S. W. (1989). Research notes and communications strategic process effects on consensus. Strategic Management Journal, 10, 295-302.

Wooldridge, B., \& Floyd, S. W. (1990). The strategy process, middle management involvement, and organizational performance. Strategic Management Journal, 11, 231-241.

Zajonc, R. B. (1968). Attitudinal affects of mere exposure. Journal of Personality and Social Psychology, 9, $1-29$. 